\title{
DE PARTIKELS $S A$ EN (DE)GO IN DE CREOLENTAAL VAN SURINAME
}

DOOR

\section{A. Donicie C.ss.R.}

„Het is verheugend", schrijft R. D. Simons in zijn artikel over het partikel $s a$, , dat het Neger-Engels hoe langer hoe meer belangstelling ondervindt en een onderwerp van wetenschappelijk onderzoek gaat uitmaken." 1 )

Wij delen volkomen in zijn vreugde en wij hopen met name, dat van sommige moeilijke punten van het N.E. steeds meer kritieken en detailstudies zullen verschijnen, om langzamerhand tot een bevredigende oplossing te komen van nog verschillende omstreden kwesties.

Een van deze kwesties betreft de waardebepaling van het partikel sa. Dr J. VOORHOEve zegt in zijn verdienstelijke dissertatie ${ }^{2}$ ) het volgende: ",de sa-categorie blijkt in de meeste gevallen een verzekering of belofte in te houden, die op zich zelf nog vrij vaag blijft. Omschrijving van de waarde: de mogelijkheid bestaat dat ...., er is kans op, dat .... Wanneer een minder vage belofte gegeven moet worden, of als men iemand groter zekerheid wenst te geven, gebruikt men het hulpwerkwoord go (letterlijk vertaald: gaan). Omschrijving van de waarde van go, aldus gebruikt: van plan zijn, vast besloten zijn, op het punt staan, voorbestemd zijn ...." Aangezien ,,mogelijkheid" en ,,er is kans op" een onwerkelijkheid aanduiden, fixeert Dr VOoRHOEve de waarde van sa nog algemener: $s a$ is de indicator van de ,,onwerkelijkheid" en consequenter heeft sa geen futuraal aspect. ${ }^{3}$ )

1) W.I. Gids 1954, p. 166.

2) Voorstudies tot een beschrijving van het Sranan Tongo, 1953.

s) Het is niet aan te nemen, dat VoorhoEve zijn term ,,onwerkelijkheid"' letterlijk zal bedoelen. Er zijn veel meer processen met onwerkelijkheid, die in het N.E. toch niet met $s a$ benoemd worden. Wij noemen: voorwaardelijke zinnen (bijv. als het regent, kom ik niet), vraagzinnen (bijv. kom je?), gebodszinnen (bijv. kom jij eens hier). Het lijkt ons veilig aan te nemen, dat hij betoelt: $s a$ noemt geringe kans op de verwezenlijking van een toekomstig proces. Hiermede vervalt dan zijn nadrukkelijk afwijzen van het futuraal karakter.

Wij stellen ons voor, dat het volgende geschied is: VOORHOEVE heeft aanvankelijk de term , onwerkelijkheid” gebruikt met de bedoeling, die wij boven aangaven en is er daarna toe gekomen haar letterlijk op te vatten. Vandaar zijn bewijs met ben $s a$ als irrealis, om daarmede de onwerkelijkheid van $s a$ aan te tonen. 
De heer Simons is het hier niet mee eens en hij haalt verschillende gevallen aan, waarin $s a+$ grondvorm niet betrekking hebben op een mogelijkheid of kans, maar op een stellige zekerheid, een vast besloten zijn, een werkelijkheid. Zijn voorbeelden uit de spreekwoorden, waarin meestal sa gebruikt wordt, zijn wel het sterkste bewijs, dat $s a$ niet als notum irrealitis kan aangemerkt worden. „Een spreekwoord”, zo zegt hij, ,,bedoelt toch niet bij een adagium een „onwerkelijkheid" of „onzekerheid” te stellen.

Wij zijn het hiermee volkomen eens. Ook ons zijn de gevallen, waarin sa geen ,"mogelijkheid”, geen „,vage belofte”, geen ,twijfel” inhoudt te dikwijls voorkomend, om $s a$ aldus te kwalificeren. We zullen dat met een paar voorbeelden nog nader duidelijk maken:

Na wet ben de: suma bosi prins, na dati sa troo nanga en (HERSK. p. 380, r. 12 v.o.). De wet was: wie de prins kust, die $z a l$ met hem trouwen. Hier is geen sprake van een twijfel of vage belofte of van ,,een mogelijkheid bestaat dat", maar van een wet. En toch is hier sa gebruikt.

In zinnen, waarin het werkwoord nader wordt bepaald door ",misschien", of waarin een twijfel wordt geschapen door een woordgroep als: ,,ik weet niet, of", zou men dan altijd $s a$ moet gebruiken volgens de waardebepaling van VoorhoEve. Toch is het gebruik van go hier heel goed mogelijk; bijv. A kan de aj go kon tamara. Misschien (lett. het kan zijn, dat) zal hij morgen komen.

Mi no sabi, efi mi de go de da twenti na neegi (Hersk. p. 334, r. 17). Ik weet niet, of ik de negen en twintigste zal zijn (die Koning zal doden).

A kan de na trawan go tajgi wi m'ma baka (HersK. p. 384 , r. 3 v.o.). Het kan zijn (misschien) dat de andere het onze moeder zal overbrengen.

In zinnen, waarin ,alle" twijfel wordt uitgesloten en niet alleen een „groter", maar een absolute zekerheid wordt gegeven door een nadere bepaling met ,,zeker", zou men dan weer go moeten gebruiken en nooit sa. Toch komt dan heel vaak $s a$ voor; bijv. Awasi san e kon, mi $s a$ go nomo nomo. Wat er ook gebeurt, ik ga vast en zeker.

De normale vorm om een ",mogelijkheid" in het N.E. te noemen, is bovendien niet $s a$, maar ,kan" of ",man”' (kunnen, mogelijk zijn); bijv. A kan de na tru. Het kan zijn (de mogelijkheid bestaat) dat het waar is. Ju sa man du so wan sani? Zul jij zo iets kunnen doen?

Het eerste voorbeeld, dat VOoRHoEve aanhaalt, om zijn mening te staven, zal dan ook meestal gegeven worden met „man": Luku na mofo na oro, efu ju no man si Konkoni (Hersk. p. 292, 33). Kijk in de opening van het hol, of je Konkoni niet kan zien.

We zijn het echter met VOORHOEVE eens dat $s a+$ grondvorm, een ,,mogelijk zijn" ,,kan" bedoelen of betekenen. Ook zijn we het met hem eens, dat ben sa voorkomt als duidelijke irrealis. Maar mag men nu aldus redeneren : ben $s a$ is duidelijk een irrealis, dus $s a$ alleen (zonder verleden tijdspartikel) ook? Dan ontstaat er een andere ernstige moeilijkheid tegen de mening van VOORHOEvE, rechtstreeks tegen zijn waardebepaling van go en zijdelings tegen $s a$. Immers, wat is het geval? In het N.E. treedt ook go (in zijn samenstelling ben de go) op, als duidelijke index van onwerkelijkheid; bijv. A jannjan ben switi, noso a no ben de go njan ala (HERSK. p. 283 , r. 11 v.o.). Het eten was lekker, anders had hij niet alles opgegeten.

Als ik nu dezelfde redenering volg als bij ben sa krijg ik het volgende: ben de go is duidelijk een index van "onwerkelijkheid", dus go ook. Zo 
kOmt VOORHOEVE in conflict met zijn eigen mening, die zegt dat go meer „werkelijkheids"-karakter heeft tegenover $s a$. Een dusdanige redenering leidt dus naar twee verschillende vormen, die beide "onwerkelijkheid" noemen. Dit laatste echter botst tegen de mening van VoorHoEvE, want in zijn opvatting hebben sa en go een verschillende waardebepaling.

Wij zijn er niet geheel zeker van, of dr VOORHOEVE als boven heeft geredeneerd. Het lijkt er meer op, dat hij na onderzoek van het feitenmateriaal tot de overtuiging kwam, dat $s a$ index irrealitatis is, en dat hij in ben sa een bevestiging van zijn mening heeft menen te vinden. Maar ook al zou hij niet de samengestelde vorm ben sa als uitgangspunt hebben genomen, maar de enkelvoudige vorm $s a$ (als volgt: $s a$ noemt onwerkelijkheid, dus ook ben sa), dan zou hij toch weer, dezelfde redenering toepassend op go, in conflict komen met zijn waardebepaling van dit partikel. Immers als go "meer werkelijkheid" zou noemen dan sa, dan ook ben de go. En dit kan weer niet, want ben de go noemt in feite ,,onwerkelijkheid".

Het over het hoofd zien van de vorm ben de go lijkt ons daarom een onoverkoombare moeilijkheid op te leveren tegen VOORHOEVE's waardebepaling van go.

R. D. Simons komt tot de volgende conclusie: het werkwoord voor de toekomende tijd is $s a$; alleen voor het futurum proximum wordt go gebruikt.

Hoeveel tijd er nodig is, om nog van een futurum proximum te kunnen spreken omschrijft Simons niet. Dit is trouwens niet altijd met de passer af te meten. Er zijn echter gevallen genoeg, waarin de aanwezigheid van een futurum proximum aan geen twijfel onderhevig is, wat bijv. het geval is, wanneer een toekomstig proces ,,aanstonds” of „,vandaag” zijn beslag zal krijgen. Wanneer dit pas over een paar maanden of nog later zal gebeuren, kan men absoluut en objectief genomen zeker spreken van een futurum remotum. Men zal echter zien, dat in beide gevallen zowel $s a$ als de go kan voorkomen; b.v.

Mi $s a$ kon wanten wanten (HersK. p. 232, r. 15 v.o.). Ik zal op staande voet komen. Na ini feefi minuut a sa wiki en baka (HersK. p. 360, r. 18). Binnen vijf minuten zal hij hem weer ten leven opwekken.

We mi sa sori ju djonsro te Hontiman pasa (Hersk. p. 310, r. 10 v.o.). Wel, ik zal het je aanstonds laten zien, wanneer Jager gepasseerd is.

Simons zelf geeft een voorbeeld met de bepaling ,,aanstonds” bij het werkwoord, waarin echter go gebruikt is. Dit geheel overeenkomstig zijn mening.

De voorbeelden met go bij een futurum proximum zijn nog met talrijke te vermeerderen; b.v. Luku bun je go fadon. Pas op, (anders) val je.

No ari a titee, noso aj go koti. Trek niet zo aan het touw anders zal het stuk gaan. Men ziet dus: bij één en hetzelfde futurum proximum zowel $s a$ als de go.

Hetzelfde verschijnsel doet zich voor bij het futurum remotum; b.v. Ma na baka tu jari mi sa kon teki en (HersK. p. 384, r. 2). Maar na twee jaren zal ik het komen halen.

Te en kon bigi en sa paj (HeRSK. p. 156, r. 12). Wanneer hij groot geworden is, zal hij betalen.

Echter: Te mi friari, mi e go puru en (Hersk. p. 420, r. 11 v.o.). Wanneer ik jarig ben, zal ik ze (de pinda's) oogsten. Uit heel het verhaal blijkt, dat 
men in het laatste voorbeeld met een futurum remotum te doen heeft.

Waarschijnlijk heeft SimoNs echter alleen willen zeggen: „overal, waar het futurum op handen is (proximum), gebruikt men de go en waar het futurum niet proximum is, kan men geen de go gebruiken, maar $s a$, waarmede ik niet wil beweren, dat waar sa gebruikt wordt niet een futurum proximum bedoeld kan zijn". In dit geval bewijzen de boven geciteerde voorbeelden met futurum proximum, waarbij sa gebruikt wordt, niets tegen deze mening van Srmons. Immers, dan neemt hij $s a$ als algemene vorm en de go als speciale vorm van het futurum en dan kan o.i. waar de algemene vorm $s a$ staat ook een futurum proximum aanwezig zijn, ofschoon niet in de werkwoordsvorm benoemd. Maar zelfs al neemt men deze theorie over taalkundige tegenstellingen niet aan, dit blijft vast staan: volgens de mening van Simons is er overal waar de go staat, een futurum proximum aanwezig. Hiertegen pleit echter het voorbeeld: te mi friari me go puru en (zie boven).

Dit voorbeeld willen we nog vermeerderen met een paar anderen:

Mi bleeti, bika na baka wan jari masra Simons e go kon baka na Sranan. (futurum remotum en toch go). Ik ben blij, want over een jaar komt meneer Simons weer naar Suriname.

Luku bun, wan dee me go sori ju. Pas op, eens zal ik je leren.

In verhaal no. 1 van Herskovirs (r. 10) vraagt Haan aan Spin, wien hij $f 50$ geleend heeft: Oten me go kisi a moni baka? Wanneer zal ik het geld terug krijgen? Hier is go gebruikt, ofschoon men toch niet bepaald kan zeggen, dat hier sprake is van een futurum proximum. Tijger echter, die in dezelfde omstandigheden verkeert, vraagt: Oten ju sa gi mi en baka? Wanneer zul je me het terug geven?

Uit dit alles blijkt wel, dat wij met SrmoNs ook van mening verschillen. Wel zijn we het met hem eens, dat $s a$ een toekomstig proces in het algemeen noemt. We geloven echter, dat, wat de waardebepaling van de speciale vorm go (futurum proximum) betreft, onze meningen niet zo heel veel verschillen en wij wel tot een overeenstemming kunnen komen, zoals we in de slotbeschouwing zullen zien.

Wij komen nu nader terug op het typisch gebruik van $s a$ in de betekenis: kunnen, mogelijk zijn. Onze nog niet gepubliceerde studie van het Saramaccaans geeft o.i. de oplossing van het raadsel. In deze taal is de enige vorm, om ,"kunnen”, ,"mogelijk zijn” te benoemen $s a$; b.v.

Sondo moni ju à $s a$ du wan hojo soni (N.B. à is ontkenning). Zonder geld kun je geen enkel ding doen.

Ju $s a$ opo di tompu dew? (dew=de+uitroep o) Kun je die trommel daar optillen? Mi swaki; me ( $e$ is op Lombe ook ontkenning) $s a$ opo. Ik ben zwak; ik kan niet opstaan.

Me $s a$ ko. Ik kan niet komen.

Het eerste voorbeeld van Voorhozve zal daarom door iedere Saramaccaan weergegeven worden met $s a$, zoals bij HersKovits; aldus: Luku a di baku buka e ja sa si Konkoni. Kijk in de opening van het hol, of je Konkoni niet kan zien.

Wij zijn daarom van mening, dat beide talen de vorm sa (kunnen) gemeen hebben. In het Saramaccaans is het de enige vorm om „kunnen" „mogelijk" zijn te noemen en in het N.E. leeft deze vorm nog schaars voort. Wij geloven daarom ook, dat de volgende voorbeelden met „kunnen" moeten vertaald worden: 
Anansi ben go stree nanga Kakalaka, suma sa kren moro hee (HERSK. p. 194, r. 6). Anansi was een wedstrijd gaan houden met Kakalaka, wie hoger kon klimmen.

Mek'den stree, suma sa ari trawan moro tranga (Hersk, no. 24, r. 1). Laten zij wedstrijd houden, wie de andere harder kan trekken.

Er zijn nog meer vormen, die de volledigheid van deze kwestie raken, waar het Saramaccaans licht op kan werpen:

a) de vorm bio.

Wij hebben in onze spraakkunst beweerd ${ }^{1}$ ), dat deze vorm een samentrekking is van ben de go. Die mening zullen wij thans moeten herzien, zoals de studie van het Saramaccaans ons weer geleerd heeft. In deze taal wordt de irrealis altijd genoemd door bio, zodat bi sa zo goed als zeker niet voor komt. Bij vijf informanten was de constante weergave van het negerengelse ben sa: bio. Deze vorm is dus geen samentrekking, maar weer gemeen aan het N.E. en het Saramaccaans, en in het N.E. zeer veel voorkomend.

Etymologisch is bio een samentrekking uit bi (Engl. been) en $o$ (Engl. go). $B i$ komt altijd niet-genasaleerd voor. Bovendien is in het Saram. de oorspronkelijke i-klank van ,,been” bewaard gebleven.

b) de vorm $o+$ grondvorm.

Ook weer een vorm aan beide talen gemeen. In het Saramaccaans bestaat zelfs go+grondvorm niet; b.v. A $o$ ko. Hij zal komen.

Het Saramaccaans heeft er ons op gespitst, om te observeren, of deze vorm ook in het N.E. voor komt, want tot nog toe hadden we deze vorm, zoals alle beschrijvers van het N.E., over het hoofd gezien, ofschoon het voorbeeld van Herskovirs ons op het spoor had kunnen brengen: Mi $o$ pur'ju. Ik zal je opnemen. (Hersk. p. 198, r. 19)

De laatste tijd hebben wij in onze gesprekken met de stadsmensen van de buitenbuurt er speciaal op gelet, of we deze vorm ook konden opvangen. De volgende drie voorbeelden hebben wij enkele weken geleden opgetekend:

Efi den paj mi moro bun, mo $o$ go drape. Als zij mij beter betalen, zal ik daar naar toe gaan, uit de mond van E.G., een Portugeese dame, 40 jaar, in Suriname geboren.

Op een erf is een politie agent, uit Creoolse ouders, 35 jaar, een auto aan het repareren. De motor wil niet starten. Ik zeg: a no wani (hij wil niet). Hij antwoordt: a $o$ go (hij zal gaan).

Een donker gekleurde dame van 25 jaar neemt afscheid van me en zegt: me gowe, noso a $o$ lati. Ik ga weg, anders zal het te laat worden.

Deze vorm brengt ons terug naar:

c) go + grondvorm.

Wij hebben in onze Spraakkunst ook gezegd, dat de twee futurale vormen zijn $s a$ en de go en dat de notatie van HersKovits, die vaak alleen go (zonder de) schrijft, foutief zou zijn. Ook dit moeten wij corrigeren. Het is wel waar, dat de go het meest voor komt, maar go alleen horen wij ook dikwijls. Dit ligt wel voor de hand ook. Als $o$ grondvorm voor komt, zal ook go (waarvan o is afgeleid) heel gemakkelijk gebruikt worden.

1) De Creolen taal van Suriname, Spraakkunst, 1954, p. 54. 
Slotbeschouwing

Wij hebben gezien, dat in $s a+$ grondvorm verschillende aspecten kunnen gevonden worden:

a) een mogelijkheid, een twijfel, een ,misschien", een onwerkelijkheid.

b) een absolute zekerheid, een algemene waarheid.

d) een futurum remotum en een futurum proximum.

Dezelfde aspecten zijn echter ook te vinden in (de)go+grondvorm. Het onderscheid tussen sa en (de)go kan dus niet liggen in bovengenoemde waardebepalingen. En zolang men het onderscheid blijft zoeken in de objectieve waarde der dingen, zal men het o.i. nooit vinden. Daarom hebben wij samen met de Heer H. Roose, litt. drs., voor de oplossing van dit probleem een subjectief element aangebracht: de gevoelsrelaties. Trouwens in een taal als het N.E. is er zeker plaats voor meer subjectiefgerichte kategorieën. $(D e)$ go noemt dus een toekomstig proces mèt affectsrelatie en $s a$ zònder deze relatie. ${ }^{1}$ )

Vandaar dus, dat sa ook meestal in de spreekwoorden voor komt. Bij een algemene waarheid immers zal er over het algemeen geen behoefte bestaan, om nog een bepaald gevoel te benoemen. Hierbij kan Simons zich ook thuis voelen, menen wij. En dit laatste geldt o.i. ook voor (de)go. Immers een toekomstig proces, waarmede men door een gevoelsrelatie verbonden is, schijnt dichter bij, dan een, waarbij dit niet het geval is. In werkelijkheid geloven wij, dat het futurum proximum van Simons psychisch bedoeld is en een minder nauwkeurige term is voor een zeer verdienstelijk resultaat van introspectie naar de betekenis van (de)go.

Antwoord van R. D. SI M O S.

Naar aanleiding van de beschouwingen van de Eerw. Pater Donicie zou ik het volgende willen opmerken.

Wij lezen: "Simons komt tot de conclusie: het werkwoord voor de toekomende tijd is $s a$; alleen voor het futurum proximum wordt go gebruikt .... Men zal zien, dat in beide gevallen (futurum proximum en futurum remotum) zowel sa als de go kan voorkomen". Waarop de schrijver drie zinnen uit Herskovits geeft, waarin voor een futurum proximum $s a$ wordt gebezigd.

Ik schreef het volgende (W.I. Gids 1954 p. 167): „O.i. is sa hèt hulpwerkwoord voor de toekomende tijd. Met daarnaast een futurumvorming met go, wanneer men een futurum proximum wil aanduiden”. „Met daarnaast" en niet ,in plaats daarvan". M.a.w. bij het futurum proximum kunnen beide partikels worden gebruikt. Alleen voor het futurum proximum wordt (ook) go gebezigd is wat anders dan voor het futurum proximum wordt alleen go gebruikt.

Ook bij het futurum remotum kan go worden gebruikt zegt de schrijver en ter adstructie daarvan geeft hij de volgende zin uit Herskovits: ,,Te mi friari, mi e go puru en". (Als ik jarig ben, zal ik - de pinda's - oogsten)

Ik vestig de aandacht op wat ik schreef op p. 174: ,, dat go ook gebruikt wordt, als nadat er aan een voorwaarde is voldaan, iets zeker en spoedig gebeuren zal”. Als voorbeeld gaf ik: „Efoe mi si hem, mi sa (de go) aksi hem

1) Met ,zonder affectsrelatie” bedoelen wij: de spreker laat in het midden, of er een affectsrelatie is of niet; het kan dus níet zo zijn, maar ook wèl. In dit laatste geval benoemt de spreker die relatie eenvoudig niet. Men bedenke dat taaltekens niet gebruikt mòeten worden. (H. RoosE) 
sainde a doe dati" (Als ik hem zie - wie weet, of en wanneer dit het geval zal zijn - zal ik hem vragen, waarom hij dat gedaan heeft.)

Welnu, in het door Pater DoNICIE gegeven voorbeeld hebben wij zoal niet met een voorwaarde dan toch met een tijdsbepaling te doen, waarbij de ene handeling ten opzichte van de andere een futurum proximum is. Mijn voorbeeld zou ook hebben kunnen luiden: ,Te mi si hem ..." (Wanneer ik hem zie ...). Dat zien kan over lange tijd plaats hebben, maar het vragen is ten aanzien daarvan ,proximaal”. Zoals in het voorbeeld van Pater DoNicie het jarig worden en het oogsten. Een jonge man kan zeggen "Te mi kom owroe, mi de go bai wan djari en mi de go kweki fowroe" (Als ik oud geworden ben, ga ik een erfje kopen en kippen kweken). Het oud worden ligt nog in ver verschiet, maar als die tijd daar is, zijn de andere handelingen futurum proximum en kan dus go worden gebruikt.

Conclusie: Pater DoNICIE en ik zijn het geheel eens.

Antwoord van J. VOORHOEVE.

In het bovenstaande artikel van pater Donicie heeft hij het waardeverschil tussen $s a-+$ verbum en go + verbum behandeld als inleiding op een liefst afdoende discussie over een moeilijk detailprobleem in de structuur van het Surinaams. Mijn bijdrage in deze discussie werd uitdrukkelijk door de schrijver gevraagd en het valt mij daarom moeilijk te moeten zeggen, dat ik op linguïstische gronden een discussie over dit probleem meen te moeten weigeren. Dit probleem kan namelijk alleen gesteld worden, wanneer men uitgaat van een linguïstische foutieve premisse. Wel kan ik en zal ik ook trachten een positieve bijdrage tot de discussie te leveren door duidelijk te maken, waarom men zich hier een verkeerd probleem gesteld heeft en hoe men tot een zuiverder probleemstelling kan komen. Dit neemt natuurlijk niet weg, dat pater DoNICIE (zoals ook op vele plaatsen in zijn grammatica) met zijn artikel verrassende nieuwe gezichtspunten opent. $\left.{ }^{1}\right)$ Deze kunnen echter eerst vanuit een zuiverder uitgangspunt op de juiste waarde geschat worden.

Pater DoNICIE vraagt zich in dit artikel af, welk verschil in taalwaarden te vinden is tussen de constructies $s a-+$ verbum en go + verbum. De vormen sa- en go zijn echter van geheel andere orde (wat ook blijkt uit het door mij gebruikte koppelteken) en daarom hebben wij te maken met twee totaal verschillende en onvergelijkbare constructies. $s a$ - is namelijk een woorddeel (een prefix, dat slechts voor verba kan voorkomen) en go is een zelfstandig woord uit de klasse der verba. De drie verbale prefixen $b e n-, s a-e n$ - kunnen in deze volgorde voor practisch ieder verbum geplaatst worden. Wij gaan uit van de zin: $m$ ben-sa-e-waka (ik prefixprefix-prefix-lopen) Wij praten met opzet niet over de betekenis, maar beschouwen hier alleen de vormen. Waarom is nu het element sa- een prefix en geen zelfstandig woord, zoals go. Wij kunnen daarvoor twee redenen opnoemen ${ }^{2}$ ): $r e$ Het element $s a$ - is niet omstelbaar t.o.v. de omringende

1) Ik denk hierbij aan zijn waardebepaling van $s a$ - als indicator van potentialis (te vertalen met „,kan”, zowel in Saramaccaans als Surinaams). Hij biedt mij hier een onverwachte en zeer welkome steun, waarvoor ik hem zeer dankbaar ben.

2) Wij baseren ons op de woordkenmerken, zoals die uiteengezet werden door prof. dr A. Reichling, „De taal, haar wetten en haar wezen”, in Ensie II, 1947, p. 39. 
elementen. Men kan dus niet zeggen : ${ }^{*} m$ sa-ben-e-waka of ${ }^{*} m$ ben-e-sa-waka. $2 e$ Het element $s a$ - is niet uiteenplaatsbaar t.o.v. de omringende elementen. Men kan bijvoorbeeld niet zeggen: ${ }^{*} m$ ben-go sa-e-waka. Op grond hiervan alleen al moet men vaststellen, dat sa- geen woord is, maar een woorddeel. Daarbij kunnen wij nog andere redenen opnoemen. Men kan $s a$ - in de constructie, waarvan wij uitgingen, niet vervangen door een verbum, tenzij men de constructie geheel wijzigt. In speciale omstandigheden kan men wellicht zeggen (ik ben daar niet eens zeker van, pater DoNicIE kan dat beter beoordelen dan ik) $m$ ben-go e-waka. Wij hebben dan echter niet te maken met een verbum waka naar tempus, modus en aspect nader bepaald door drie prefixen, maar met een verbale groep go waka, naar de tempus bepaald door ben-, terwijl het laatste element van de verbale groep bovendien nog naar het aspect bepaald wordt door $e$ Tenslotte kan men go duidelijk als verbum herkennen, omdat dit element de verbale prefixen voorgevoegd kan krijgen ( $m$ ben-sa-e-go), terwijl dit met het element sa- beslist niet mogelijk is $\left({ }^{*} m\right.$ ben-sa-e-sa). Dit is geen aardig gegoochel met vormen en mogelijkheden, maar het linguïstisch bewijs van het essentiële verschil tussen de elementen $s a$ - en $g o$.

Waarom zou men dan eventueel toch niet mogen spreken over het verschil in waarde tussen de constructies $s a-+$ verbum en go + verbum ? Omdat het verschil tussen $s a$ - en go veroorzaakt, dat wij hier te maken krijgen met twee geheel verschillende en onvergelijkbare constructies. Wij hebben te maken met een verbale vorm (sa-verbum) en een verbale groep (verbum + verbum). Het zal wel uitkomen, dat er verschil bestaat tussen deze verschillende constructies. Er bestaan zoveel verschillende constructies in een taal (bijvoorbeeld: adjectivum + substantivum en substantivum + substantivum). Wij kunnen het verschil tussen dergelijke constructies pas bespreken, wanneer wij de constructies kunnen vergelijken, wanneer er een vergelijkingsbasis gevonden kan worden.

Pater Donicie meent wellicht, dat de semantische overeenkomst tussen de beide constructies hem een vergelijkingsbasis verschaft. Semantische overeenkomst vinden wij echter ook tussen $e$ - + verbum en kon of bigin + verbum. Zie daartoe de volgende, gedeeltelijk uit de grammatica van Donicie geputte voorbeelden:

$m e-n a t i=m e-k o n$ nati $=\mathrm{ik}$ word nat; $m e$-sabi-pasi $k b a=m e$-bigin sabi pasi $k b a=\mathrm{ik}$ begin te-kennen de-weg reeds. Waarom worden deze problemen nooit aan de orde gesteld?

De reden dat men het probleem sa-/go (en dat dateert al van heel vroeger) als zo bijzonder belangrijk naar voren geschoven heeft, schuilt ergens anders. De Europese tempuscategorie futurum kan in het Surinaams op twee wijzen worden weergegeven, $\mathrm{nl}$. door $s a-+$ verbum en door go + verbum. Men is er daarom van uit gegaan, dat er dus twee futura waren in het Surinaams en beijverde zich de mogelijke verschillen tussen beide futura te vinden. Hiermee zet men echter het taalkundig onderzoek op zijn kop. Men is uitgegaan van een methodisch onjuist uitgangspunt en zo tot een verkeerde probleemstelling gekomen. Discussie over het verschil tussen $\mathrm{sa}$ - + verbum en go + verbum heeft daarom ook weinig zin.

Men moet uitgaan van het Surinaamse verbum. Dan zal men constateren, dat ieder verbum in het Surinaams door middel van verbale prefixen in acht verschillende vormen kan voorkomen (waaronder niet de constructies go, kon of bigin + verbum, wel echter de constructie sa- + 
verbum). Pas hierna kan men het verschil in waarde tussen de acht verbale vormen vaststellen en tot een waardebepaling van de functie der prefixen komen.

Bij dit laatste onderzoek is de hulp van taalkenners als pater A. Donicie en de Heer R. D. Simons onmisbaar. Zij immers kunnen door hun jarenlange intensieve contact met de taal de categoriale verschillen veel beter van binnen uit benaderen dan ik. Men moet echter de discipline van de vorm durven aanvaarden, omdat men anders om de problemen heen blijft denken. Het lijkt mij daarom goed, dat ik mijn bijdrage in de discussie op deze punten heb gericht.

$\mathrm{Ik}$ zou gaarne willen voorstellen de discussie uit te stellen tot na het verschijnen van een uitvoerig artikel van mijn hand over het verbale systeem in het Surinaams. Hierna zouden wij gezamenlijk kunnen komen tot een zuiverder waardebepaling van de daarin geordende verbale categorieẻn.

We derwoord van A. Don ICI E C.ss. R.

Aangezien de heer Simons verklaart het geheel met ons eens te zijn, behoeven wij op zijn antwoord niet nader meer in te gaan.

In zijn proefschrift heeft $\mathrm{dr}$ VOORHOEVE, zonder voorafgaande theorie over lexicale taalelementen (dus intuïtief) de werkwoordskategorieën $s a$ en go met elkaar vergeleken, zoals wij dat hebben gedaan.

In zijn huidig betoog komt hij daarvan terug op taal-theoretische gronden, die echter onze intuïtieve zekerheid, dat die beide kategorieën vergelijkbaar zijn, niet kunnen verstoren. Daar wij ons echter liguïstisch niet voldoende geschoold achten, om hem te beantwoorden, hebben wij een beoordeling van dr VOORHOEVE's nieuwe mening gevraagd aan onze regelmatige medewerker $\mathrm{H}$. RoosE, die het volgende opmerkt.

Dr VOORHOEve is tot de conclusie gekomen, dat $s a$ geen, go wel zelfstandige betekenis heeft. Dat ben ik met hem eens.

Daaruit trekt hij dan weer de verdere conclusie, dat die lexicale elementen niet vergelijkbaar zouden zijn. Hier echter heeft hij niet doorgeredeneerd. Als structureel linguïst had VoorHoEvE de oppositie tussen die beide lexicale elementen moeten onderzoeken. Hij zou dan tot de ontdekking gekomen zijn dat die aldus was:

$\underline{\text { Zonder participerende betekenis }}$ met participerende betekenis woord uitgang, partikel enz.

Door de aard van deze tegenstelling (algemeen-speciaal) is het theoretisch mogelijk, dat een woord (zonder participerende betekenis) gebruikt wordt waar een uitgang of partikel (met participerende betekenis) nauwkeuriger zou zijn. Deze theoretische mogelijkheid doet zich nu voor bij go: het heeft inderdaad geen participerende betekenis, maar in de combinatie ",me go kon" heeft het participerende bedoeling. En in deze bedoeling is het dus wel degelijk vergelijkbaar met $s a$. Als bewijs van de niet-zelfstandige bedoeling van go in de hier besproken combinatie kan nog gelden, dat daarnaast voorkomt de combinatie $o+$ grondvorm, welke zelfs geen zelfstandige betekenis heeft. De vorm $o$ kan immers niet de totale woordinhoud van een zin uitmaken.

Paramaribo, Nov. 1955 